\title{
ACTORES Y PROCESOS DE CAMBIO: LA ELITE ECONÓMICA DEL "GRAN CONCEPCIÓN" Y EL PROYECTO NEOLIBERAL (1973-1983)*
}

\author{
ACTORS AND PROCESSES OF CHANGE: THE ECONOMIC \\ ELITE OF "GREATER CONCEPCIÓN" AND THE NEOLIBERAL \\ PROJECT (1973-1983)
}

\section{DANNY MONSÁLVEZ ARANEDA*", LEÓN PAGOLA CONTRERAS}

\section{RESUMEN}

El presente artículo busca analizar la influencia que tuvo el neoliberalismo en Chile a en los espacios locales, en este caso en el "Gran Concepción”. Para aproximarnos a aquello, examinaremos cómo el proyecto económico de la dictadura cívico militar a través de los economistas formados en Chicago logró concretarse a nivel regional sobre la base de determinados planes e iniciativas. Asimismo, se identificarán y caracterizarán algunos actores económicos del periodo, los espacios de sociabilidad y de difusión a través de los cuales circularon las ideas neoliberales en vista a su implementación.

Palabras clave: Chile, dictadura cívico-militar, neoliberalismo, Gran Concepción, elite económica.

\section{ABSTRACT}

This paper seeks to analyze the influence neo-liberalism had in Chile on the level of local spaces, in this case the Greater Concepción area. In order to approach this mat-

* Este artículo forma parte del proyecto Fondecyt Regular № 1120009 "Poder, prestigio y riqueza: Transformación de la elite regional en el 'Gran Concepción'. Del Estado desarrollista al Estado neoliberal 1957-1990"

** Doctor en Historia. Académico de Historia Política de Chile Contemporánea en el Departamento de Ciencias Históricas y Sociales, Universidad de Concepción. Concepción, Chile. Coinvestigador del proyecto. Correo electrónico: dannymonsalvez@udec.cl

*** Licenciado en Ciencias Políticas y Administrativas, Universidad de Concepción. Alumno del Programa de Magíster en Investigación Social y Desarrollo, Universidad de Concepción. Concepción, Chile. Ayudante de investigación del proyecto. Correo electrónico: lpagola@udec.cl 
ter, we will study how the civil-military dictatorship and Chicago-trained economists managed to position their economic project at a regional level through specific plans and initiatives. In addition, we will also identify and characterize some economic actors of the period and the places of sociability and diffusion through which neoliberal ideas circulated considering their implementation.

Keywords: Chile, civil-military dictatorship, neoliberalism, Greater Concepción, economic elite.

Recibido: 29.09.14. Aceptado: 22.12.14.

\section{INTRODUCCIÓN}

$\mathrm{P}$ RODUCIDO EL GOLPE de Estado de 1973, uno de los principales objetivos que se propuso la Junta Militar de Gobierno fue el llamado proceso de "Reconstrucción Nacional", lo anterior a consecuencia de la crisis institucional provocada -a juicio de los militares y civiles prodictadura- por la administración del Presidente Salvador Allende. En vista de aquello, la tarea "restauradora" conllevó impulsar significativas transformaciones para retornar el país a la normalidad y al sitial que había perdido en los últimos años de gestión socialista. De esta forma, la administración del país bajo "mano militar" experimentó intensos cambios a nivel de funcionamiento e institucionalidad, imponiendo una modificación de modelo económico, el cual, sin duda, pasó a constituirse en uno de los pilares fundamentales de la transformación estructural llevada adelante por la dictadura cívico-militar que encabezó el general Augusto Pinochet. Transformación que no sólo afectó la estructura macro-económica y financiera de Chile, sino también a los diversos grupos sociales del país. En ese sentido, el cambio del modelo económico, pasando de una significativa presencia del Estado, a otro plenamente abierto respecto del mercado mundial y con un rol netamente "subsidiario" estatal, trajo cambios significativos, no sólo a nivel central, léase Santiago, sino también a nivel de espacios regionales y locales.

Como una forma de adentrarnos en este proceso de cambios, daremos cuenta, en una mirada de conjunto, de la aplicación del llamado "experimento neoliberal" en el "Gran Concepción"1, particularmente durante los

\footnotetext{
${ }^{1}$ Entendemos por Gran Concepción "aquella conurbación urbana constituida por la ciudad de Concepción como centro direccional de operaciones públicas y privadas; el complejo portuario industrial siderúrgico y petroquímico Talcahuano-San Vicente; Penco y Lirquén como espacios tradicionales de la loza y el vidrio; Chiguayante como centro textil. A lo cual se agrega en el extremo norte de esta conurbación el tradicional e histórico centro textil de Tomé y en el extremo sur, las localidades de Coronel y Lota, como ciudades del carbón” (Hernández, 1983).
} 
primeros diez años, en la cual los distintos actores y sectores económicos fueron construyendo y utilizando las instituciones del Estado para concretar sus objetivos hasta la crisis económica del año 1983.

\section{ALGUNOS ANTECEDENTES}

Tras el 11 de septiembre de 1973 el "Gran Concepción" vivió una gran expectación e incertidumbre, particularmente sobre lo que sería la nueva conducción militar que se había hecho del poder. La prensa local hacía prever el giro rotundo que tendría la conducción política y el manejo económico a nivel de empresas, industrias y el sistema financiero, el cual pasó a control del mundo privado, específicamente a determinados grupos económicos de la época, marcando de inmediato una diferencia con lo que ocurría hasta al momento de la intervención militar del día martes 11, donde el Estado, por ejemplo, controlaba catorce de los diecisiete bancos comerciales del país a través de la Corporación de Fomento de la Producción (CORFO), como lo planteara Dahse (1979, pp. 148-189).

Ya a fines de 1973 se inició una considerable privatización de la economía. De aproximadamente 500 empresas -industrias, minas, bancos, compañías de seguro, etc.- controladas por el Estado antes del golpe militar, y que en muchos casos habían estado bajo propiedad durante decenios, alrededor de 475 habían sido vendidas al sector privado al año 1980. El proceso de privatización del sector productivo fue particularmente espectacular a contar de 1975, cuando muchas empresas estatales fueron vendidas -a precios ridículos, a veces- a un puñado de grupos económicos (Vylder, 1985, p. 8).

Después del 11 de septiembre el sector privado -entre ellos el financiero- pasó a constituirse en uno de los pilares fundamentales para comenzar a generar las condiciones e instancias necesarias de proyección económica que interesaban tanto a las autoridades militares como civiles de la época, entre ellos, la elite económica y los gremios empresariales, que tenían mayor poder e influencia en el "Gran Concepción".

Cabe señalar que gran parte de estos sectores que funcionaron durante los primeros años de dictadura en la zona penquista pertenecieron principalmente a personeros de la capital del país, los cuales a través del sector financiero desempeñaron un papel fundamental en el proceso de concentración de capital y acumulación de riqueza, esto por supuesto no sólo en el 
"Gran Concepción", sino también en el resto de las regiones del país (Dahse, 1979, pp. 138-147).

El mundo empresarial de Concepción estaba representado en diversos gremios $^{2}$, por ejemplo, la Sociedad Agrícola del Sur, la Asociación de Artesanos Medianos y Pequeños Industriales (AMPICH), la Confederación de Dueños de Camiones de Chile (SIDUCAM), los sectores de la producción y el comercio en la Cámara de la Producción y Comercio de Concepción, y el sector de la construcción, entre otros, los cuales se asociaron e invirtieron junto a empresarios capitalinos pertenecientes a los grupos económicos más grandes de Chile. Además contaron con la venia y aprobación de las autoridades de la zona que representaban el poder político de la Junta Militar de Gobierno. La síntesis de aquel escenario fue la relación que se dio entre los grandes capitales de Chile, representados a través del sector financiero y mercado de capitales, junto al sector de los gremios de la región y la presencia de los militares a través de instituciones como la ORPLAN (Oficina Regional de Planificación) 3 , CORFO (Corporación de Fomento de la Producción) y el Banco Central, los cuales crearon las condiciones y dieron el resguardo necesario para que se abrieran paso las nuevas instituciones que serían las responsables de poner en marcha el proceso de capitalización de los recursos de la elite económica del "Gran Concepción”, en los inicios de la dictadura cívico-militar.

Hacia 1973 poco y nada se vislumbraba en las páginas de la prensa local sobre estas relaciones antes descritas; más aún, por el ambiente de inestabilidad institucional que se vivía, los gremios y empresarios del "Gran Concepción" buscaron para entonces algunas vías que sirvieran de puentes o nexos para materializar algunos de sus proyectos; por lo tanto, si bien los primeros meses post golpe de Estado, es decir, entre septiembre y diciembre de 1973, la tarea de los militares fue de "normalización" del país, aquello no fue impedimento para que se estrecharan algunos lazos entre el mundo empresarial, gremial y las nuevas autoridades militares de la zona.

Con el pasar de los meses y ya en 1974, se dieron las primeras muestras de lo que sería por aquel entonces el camino que debía seguir la economía

\footnotetext{
${ }^{2}$ Dichos gremios debido a su extensión no se han incluido en el presente artículo, no obstante aquello, pueden ser solicitados a los autores del artículo.

${ }^{3}$ Cuando se crea la ODEPLAN (1967) en el Gobierno de Eduardo Frei Montalva, ésta obtiene la calidad de servicio público descentralizado, con patrimonio propio, y pasa a crear Oficinas Regionales de Planificación que, con el correr de los años, serían luego llamadas Secretarías Regionales de Planificación y Coordinación (SERPLAC).
} 
chilena. En nota publicada por diario El Sur, el presidente de la Sociedad de Fomento Fabril, Orlando Sáenz, señalaba los mecanismos de cómo debía operar la economía nacional; más aún, debido a las características nacionales y "espirituales" de los chilenos, dejando en claro el papel subsidiario del Estado, estableciendo que a contar de ese momento sería, en palabras de uno de los máximos dirigentes empresariales, una economía estrictamente monetaria-mercantil, que llevaría por el buen camino a las empresas nacionales (El Sur, 9 de enero de 1974, p. 3).

\section{LA ALIANZA EMPRESARIAL ENTRE SANTIAGO Y CONCEPCIÓN}

Como señala Vylder, la elección del modelo neoliberal correspondió a una alianza política entre la dictadura y un determinado sector del mundo empresarial, el financiero, "que dentro de poco llegó a hegemonizar, junto con los militares, el aparato de Estado. Al parecer, no era este el sector que estaba en primera línea de la lucha política contra Allende -los banqueros no suelen aparecer en las barricadas- pero sí fue la fracción de la burguesía que estaba mejor preparada para presentar un proyecto económico coherente a las nuevas autoridades militares" (Vylder, 1985, p. 11).

Para mediados de 1974 el camino ya parecía cobrar forma en la Junta Militar y la posición a favor de la economía social de mercado ganaba terreno para comenzar a funcionar sin mayores problemas. Por otro lado, en el "Gran Concepción" se informaba sobre los grandes avances en el apoyo al fomento de nuevas iniciativas que se presentaban en la zona. Uno de aquellos proyectos, anhelado por la elite económica penquista, fue el Banco de Fomento Regional del Bío-Bío ${ }^{4}$, iniciativa ampliamente aplaudida por la prensa local, la cual consideó a dicho banco como uno de los proyectos más importantes impulsados por el multigremio de la zona.

Como habíamos señalado, el sector financiero fue ampliamente dominado por grupos económicos de gran capital, éstos se hicieron presentes en el "Gran Concepción" abarcando ampliamente el sector crediticio e incorporando no sólo a los bancos como un instrumento de préstamos para los habitantes de Concepción y sus alrededores. También pasó a cumplir un rol activo el ámbito de las financieras de la época, las que, aprovechando la

\footnotetext{
${ }^{4}$ Respecto del Banco de Fomento Regional del Bío-Bío, véase nuestro artículo "Sueño, realidad y frustración: Banco de Fomento Regional del Bío-Bío, un proyecto de la élite económica del 'Gran Concepción' (1974-1982)” (Monsálvez y Pagola, 2014, pp. 49-58).
} 


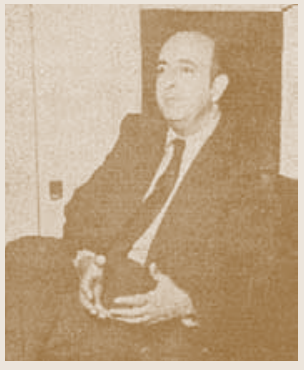

J. Cauas escasa legislación sobre el funcionamiento del mercado financiero, fueron mucho más rentables para sus dueños que los bancos, ya que su accionar era mucho más simple y expedito en materia crediticia de lo que eran aquellos en su momento, incluso funcionando al borde de la legalidad durante bastantes años (Vergara 1996, pp. 335-345).

Las financieras ${ }^{5}$ fueron, dentro del mercado de capitales, una de las formas de captación de recursos y préstamos ampliamente respaldada por la Junta Militar, como señaló el Ministro de Hacienda de la época, Jorge Cauas. La reglamentación de las financieras, a través del Decreto Ley $\mathrm{N}^{\circ}$ 637 (1974), daba un nuevo impulso al mercado de capitales y resguardaba la seguridad de los clientes, para que funcionara de manera sana y no se viera afectado el sistema financiero nacional (El Sur, 27 de septiembre de 1974, portada y p. 6).

Observaremos cómo durante el periodo estudiado se da una convivencia y estrecha relación entre la elite económica, presente en los multigremios de la Región del Bío-Bío con empresarios y capitales de Santiago; además, la inclusión de las autoridades militares durante el primer periodo de impulso a la actividad económica bajo un nuevo modelo, creó las condiciones necesarias para transformar el espacio financiero local en un terreno propicio para la captación de créditos y préstamos, no sólo en moneda nacional sino también en dólares, que serán los más cotizados durante la última mitad de los setenta, lo cual, sumado a la débil implementación de un sistema cambiario, terminará por afectar gravemente a las mismas instituciones que proporcionaron los préstamos; por consiguiente, a los proyectos financieros de la época que radicaron su trabajo en Concepción.

Esto se vio reflejado principalmente en cómo se caracterizaba el trabajo y los roles de la sociedad para las autoridades de la zona, la mezcla de factores, pero, sobre todo, la total independencia de ellos. En una inserción de diario El Sur se entregaban las pautas que debía seguir el gobierno, la universidad y la empresa para que todo funcionara coordinadamente y en un determinado orden, funcional al proyecto neoliberal impulsado por la dictadura: “... el gobernante se dedique a gobernar, el empresario se dedique a producir y el universitario a estudiar. Cuando Gobierno, Universidad

\footnotetext{
${ }^{5}$ Sociedades creadas con un menor capital, donde no se pueden crear cuentas corrientes y tampoco podrán realizar operaciones en monedas extranjeras. En la década del '70, muchas de aquellas actividades fueron también parte de los movimientos comunes de estas sociedades, haciendo difícil el trabajo de los bancos, puesto que funcionaron como competencia de dichas clásicas instituciones, aquello como forma de libertad de acción en materia económica concordante con el enfoque económico del mercado.
} 
y Empresa marchen en franca unión respetando las actividades de cada sector, se empezará a sentir un progreso verdadero y firme en nuestros países" (El Sur, 22 de abril de 1974, p. 12).

La idea era separar al Estado del mercado como actor preponderante de éste y ubicar a la universidad como una fuente generadora de profesionales, "técnicos" o "expertos", al servicio de la producción de la empresa privada, que, como se desprende de las múltiples declaraciones de los sectores productivos de aquel entonces, era la encargada de la reactivación de la economía nacional. "Cuando se rompe este equilibrio, se corre el riesgo de caer, tarde o temprano, bajo un régimen despótico, dictatorial y totalitario" ( $E l$ Sur, 22 de abril de 1974, p. 12).

El rol preponderante de la empresa privada en la economía durante la dictadura constituyó un momento importante para la elite económica en la región. Con motivo del aniversario número 103 del Banco de Concepción, su gerente general, Otto Bennewitz, señalaba la importancia que tenía la banca y sobre todo su institución como una ventana hacia el extranjero en materia de desarrollo regional y, al mismo tiempo, la gran labor que ejercía el banco sobre todo en materia de importaciones, las cuales -según Bennewitz- habían entrado en un periodo de repunte "extraordinario", lo cual se explicaba por la modernización que experimentaba la empresa regional, fundamental en el crecimiento que estaba notando la economía de la región (El Sur, 17 de octubre de 1974, p. 6).

Bennewitz calificaba al Banco de Concepción como "la palanca del desarrollo regional", sin embargo, la gran cantidad de operaciones en moneda extranjera que comenzó a inundar el mercado de capitales regional no era parte de la explicación de desarrollo de una mejor economía en la región, ni menos por la capacidad de las empresas para producir y hacer crecer el mercado, sino que era producto de la gran gestión que tenía el mismo banco para generar dichas operaciones, las cuales se concretaran especialmente en dólares. Sumada a esta situación, el traspaso a fines de 1974 de la banca al sector privado pasó a constituir el último elemento importante en lo que sería la concentración de capitales a nivel financiero (Dahse, 1983, pp. 67 a 69). Las instituciones financieras pasaron a constituirse en verdaderas delegaciones de los grupos económicos en la región y los multigremios pasaron a ser sus principales clientes, junto con las personas naturales que ocupaban los cuantiosos créditos que otorgaban las instituciones en la región.

A fines de 1974 se puso en marcha una reforma tributaria y bancaria de gran amplitud, la cual buscó reducir el tamaño del sector y mejorar -según palabras del Ministro de Hacienda Jorge Cauas- el funcionamiento de éstos 
y del mercado de capitales. La reforma a la banca consistió principalmente en la fusión de algunas entidades cercanas, ya que el incipiente proyecto de regionalización elaborado por la Junta Militar necesitaba indispensablemente que en las regiones se concentrara un capital suficiente para llevar a cabo la descentralización administrativa del país.

Otro de los cambios que introdujeron a la banca, fue la facilidad para crear organismos de fomento, tales como el citado Banco de Fomento Regional del Bío-Bío, primera institución de este tipo en el país. El Decreto Ley $\mathrm{N}^{\circ} 749$ promovió la fusión de dichas entidades para concentrar de mejor manera el capital presente en las regiones y entregar efectivamente un control mucho más disciplinado del mercado de capitales al sector privado, el cual manejó la banca en regiones (El Sur, 13 de noviembre de 1974, p. 16).

\section{EL EXPERIMENTO NEOLIBERAL Y EL “MILAGRO CHILENO” EN CLAVE LOCAL}

Existe un consenso en los investigadores de las ciencias sociales que han estudiado el periodo de la dictadura en Chile en señalar que 1975 es el punto de partida definitivo del proyecto neoliberal; es por esto que ya con los ajustes legales pertinentes con la gran mayoría de las empresas e industrias, que habían sido intervenidas antiguamente por el Estado y devueltas a los sectores privados, se inició un proceso liberalizador de la economía nacional, reflejado en un amplio impulso a las importaciones y las exportaciones, apoyado financieramente por un mercado de capitales también en manos de agentes privados que paradójicamente eran dueños de una gran cantidad de las empresas e industrias que fueron restituidas en 1975.

El caso del repunte de las empresas e industrias del "Gran Concepción" fue el tema principal de la prensa en 1975. Un gran número de información aparecida, por ejemplo, en diario El Sur sobre el manejo económico de las industrias da cuenta hasta esa fecha que la recuperación económica, en franca apertura al mercado, resultaba esperanzadora de la reactivación efectiva del mercado nacional (El Sur, 2 de enero de 1975, p. 5). En la zona las principales actividades económicas como la industria del acero, los yacimientos carboníferos, la empresa portuaria, la industria textil, el sector de la construcción y el comercio, eran las protagonistas del repunte que señalaba de manera periódica el principal diario de la zona.

Concepción se había consolidado como una excelente plaza para el mer- 
cado de capitales, puesto que la gran cantidad de bancos comerciales que se establecieron en la región y en el sector del "Gran Concepción” hicieron posible un despliegue financiero que no sólo era beneficioso para las industrias y empresas de la zona, sino que fueron un importante aval crediticio para personas naturales que buscaron en los créditos a corto y mediano plazo una alternativa para el mejoramiento de su propia calidad de vida (El Sur, 23 de marzo de 1975, p. 17). Es por este motivo que hacia 1978 la cantidad de sucursales bancarias, financieras y de cooperativas fue bastante grande, captando clientes en varias ciudades del "Gran Concepción”, según lo que se desprende de lo señalado en la revista Información Financiera de la Superintendencia de Bancos e Instituciones Financieras de octubre de 1978, donde se establece que el número de sucursales es 67.

Hay un factor que va sumado a esto. Nos referimos a la importante labor que cumplió la elite intelectual circunscrita en ese tiempo a la Universidad de Concepción. Su labor académica, en cuanto a explicar el proceso económico en marcha, fue de gran valor al momento de situar los fundamentos teóricos y conceptuales que debían obtener las empresas e industrias presentes en la zona.

Otro aspecto a señalar para comprender el momento de gran repunte destacado por la prensa a nivel local lo constituyen los seminarios empresariales dictados por el Instituto Chileno de Administración Racional de Empresas (ICARE), a partir de los cuales se generó una serie de cursos, seminarios y charlas acerca de la administración de la empresa, para su adaptación al nuevo escenario económico que se presentaba firmemente en marcha y para la especialización de los empleados de las instituciones que quisieran asistir (El Sur, 11 de noviembre de 1975, p. 4). Cabe señalar que los seminarios y reuniones empresariales patrocinados por ICARE no eran los únicos que se dictaron en la zona durante aquellos años. El hecho de que organismos como la Escuela Empresarial Andina ${ }^{6}$ efectuaran sus reuniones y encuentros en la ciudad daba también luces sobre el momento reactivador de la economía nacional y regional (El Sur, 25 de marzo de 1975, p. 3). De esta forma, se produce una mancomunión entre el mundo privado y el académico, vinculado a la Universidad de Concepción, gracias a la intervención militar (rectores delegados). La Facultad de Economía de la Universidad sentaba las bases de una nueva forma de pensar la economía,

\footnotetext{
${ }^{6}$ Esta escuela empresarial forma parte del llamado “Convenio Andrés Bello”, el cual consiste en procesos de integración educativa, científica, cultural y tecnológico iberoamericano. Es una organización de carácter intergubernamental-internacional que tiene sus orígenes en el año 1970.
} 
y su modo de operación efectiva era impulsado por una elite económica junto a los multigremios de la zona. Todo ello, por cierto, con el respaldo de la elite política-militar a cargo del aparato estatal.

De los seminarios y congresos empresariales que se dieron en la zona, son un buen ejemplo los cursos dictados en colaboración con la Universidad de Concepción para el comercio y la pequeña industria. Éstos entregarían los conocimientos básicos de economía y su relación con la sociedad. En consecuencia, importante fue el papel que cumplió durante el año 1975 la Escuela de Economía en materia de seminarios y congresos respecto de la política económica del gobierno y su implicaciones para las empresas, industrias y sobre todo para el mercado de capitales y la correcta adecuación e implementación del modelo económico de mercado ( $E l$ Sur, 19 de junio de 1975, p. 3). Este último, basado en la liberalización de la economía, la libre competencia, lejos del intervencionismo estatal y dejando a éste sólo en un rol subsidiario. Este periodo es el punto de partida de la reestructuración del modelo a nivel administrativo para conformar los ajustes financieros en la medida en que fueran necesarios, por sobre todo en el mercado de capitales nacionales y en el ajuste bancario para comenzar una nueva etapa en la economía regional.

La situación de la economía en 1976 fue favorable para el desarrollo de un sistema crediticio bastante amplio. Por ejemplo, el Banco de Concepción creó su propio departamento de ahorro, con lo cual buscó captar el capital necesario para crear un sistema de crédito lo bastante grande y capaz de poder dar el suficiente respaldo a los créditos que se otorgarían mediante las bajas tasas de encaje bancario que fijaba el gobierno, puesto que, según la lógica de los economistas neoliberales, el crédito era una buena herramienta para incentivar la inversión y el emprendimiento de nuevos negocios por parte de la población ${ }^{7}$.

Para aquel año ya se cuenta con un mercado financiero estable en la región y las distintas entidades bancarias presentes en la capital penquista se sitúan como grandes alternativas en cuanto a crédito se trataba. Dentro de este esquema, la economía se vuelve algo cotidiano entre las páginas de

\footnotetext{
${ }^{7}$ Esto consistía en crear departamentos de ahorro en diversas entidades bancarias, con lo cual podrían ocupar parte del encaje bancario para otorgarlo en forma de crédito. Las tasas fijadas para los depósitos a la vista en 1976 eran de un 85\% y un 20\% para los depósitos de ahorro según lo informaba diario El Sur de Concepción (el día domingo 25 de abril de 1976, en sus páginas 9 y 16 se habla sobre la nueva reforma a los encajes bancarios) en abril de ese año, con lo cual podían ocupar para dar créditos u otras operaciones bancarias un 15\% de los primeros depósitos y un $80 \%$ de los segundos.
} 
diario El Sur y es justamente dentro de este medio donde las ideas neoliberales se van presentando de manera inequívoca frente a un público que espera expectante las directrices que emanaban desde la Junta Militar para reorganizar al país.

A finales de agosto de 1976 aparece un reportaje sobre la economía social de mercado y sus características. A esta crónica, si bien no es la primera, se va sumando a una serie de entrevistas, editoriales y columnas de opinión donde se hace presente que el camino correcto para la conducción del país es una economía abierta al mercado, proclive a dar mayor libertad y mayores facilidades para negociar sin tanta intervención estatal (El Sur, 29 de agosto de 1976, p. 2).

Un hecho importante para entender cómo sería el siguiente paso en cuanto a comercializar bajo este nuevo paradigma económico, aparecerá en octubre de 1976, con la nueva modalidad crediticia, donde los créditos en dólares serán de ahora en adelante lo común dentro del mercado de capitales nacional, generando una entrada abrumadora de divisas, lo que traerá grandes problemas para los años siguientes, desenlace poco esperado por los promotores del neoliberalismo.

En Concepción se vive un clima de seguridad financiera. El "Gran Concepción” pasa sin sobresaltos el terremoto financiero que se está viviendo en el país, más aun cuando por esos mismos meses se presenta una nueva legislación sobre regulación bancaria y financiera ( $E l$ Sur, 5 de enero de 1977, pp. 3 y 8). El Decreto Ley 1.683 (1977) fue el punto de partida de esta nueva regulación, la cual fue necesaria para controlar el desborde de capitales que se venía generando gracias al mercado informal, que se venía dando desde hace un tiempo y estaba creando problemas reales a entidades comerciales como los bancos, siendo estos realmente afectados al no contar con la suficiente solvencia debido a las pocas captaciones.

\section{AD PORTAS DE LA CRISIS: QUE VUELVA EL ESTADO}

A consecuencia de los problemas que comenzaba a mostrar en algunos aspectos el sistema financiero nacional, especialmente debido a las malas prácticas que se presentaron en bancos y financieras, algunas entidades bancarias presentes en la región vieron afectadas sus captaciones y los créditos otorgados. Este momento tenso se vivió con gran recelo por quienes hacían uso del nuevo mercado de capitales, a tan sólo dos años del inicio de funcionamiento. 
El alto encaje que vivían los bancos en cuanto a depósitos a la vista hacía que sólo contaran con una fracción del dinero para poder poner en circulación en forma de crédito. Esto, sumado a la baja en las captaciones de ahorrantes, hizo que la liquidez con que contaban las instituciones bancarias se viera gravemente afectada a un año de ser anunciado un repunte en el mercado de capitales. Se sumaba al difícil momento financiero, la capacidad crediticia con altas tasas de interés, que fue rechazada por sectores que veían su actividad poco beneficiada en la región, principalmente los rubros agrícola y forestal.

La duda que puede plantearse frente a este momento sale a relucir cuando Patricio Ojeda, gerente de marketing del Banco de Fomento Regional del Bío-Bío y académico de la Escuela de Economía y Administración de la Universidad de Concepción, en una entrevista concedida al diario El Sur, planteó que gracias al ahorro y las iniciativas del sector privado se pueden superar algunas falencias económicas propias del periodo, puesto que, pese al momento de poca confianza que se vivía respecto del mercado, el ahorro privado se veía fuertemente beneficiado ya que superaba el año plazo $(E l$ Sur, 10 de abril de 1977, p. 15). Pese a todo esto, hacia fines del año 1977 y luego de varios ajustes, la economía vuelve a cobrar el rumbo esperado por los economistas neoliberales y, en ese instante, el sector financiero alcanza la solidez esperada, con mayores captaciones y créditos concedidos, pero con la gran sorpresa de que el dólar gana terreno importante para la economía nacional y de la región.

El momento económico es favorable, parece ir ganando terreno y así comenzar a dar mayores libertades y facilidades para contratar diversos tipos de créditos en elevados montos, además de poder obtener dólares, esto como punto importante para entender, en parte, lo que ocurrirá con la crisis de 1982. Todo esto se va haciendo presente cuando en 1977, a través de una declaración pública, el Ministerio de Hacienda dio cuenta de los avances realizados en materia económica y cómo esto progresivamente, gracias al nuevo modelo, comenzaba a cambiar el panorama económico nacional, abriendo nuevas oportunidades para el desarrollo de mejores oportunidades y mayores libertades (El Sur, 26 de agosto de 1977, portada y última página).

La "explosión financiera" del país se hizo sentir fuerte en Concepción y los créditos financieros golpearon la economía regional, haciéndose común, por ejemplo, apreciar en las páginas de diario El Sur los avisos sobre el crecimiento de capitales bancarios locales y el acercamiento de la población con el dólar, al ser frecuente el cambio para comprar diversos bienes de 
consumo o de capital indiscriminadamente, inundando a la región en un mar de créditos y préstamos otorgados no tan solo por los bancos comerciales sino que a éstos se les sumaban las financieras y bancos de fomento existentes a la fecha.

En 1978 la economía nacional dio gala de grandes avances en modernización financiera y captación de recursos, lo cual fue ampliamente difundido en los medios de comunicación nacional y regional. Se daba cuenta de que los avances realizados por la transformación radical en la conducción económica habían facilitado las libertades para poder realizar los cambios necesarios, fomentando el emprendimiento y el desarrollo de lo que sería, para las autoridades de la época, el principal motor del crecimiento del país: la empresa privada.

Lo anterior fue parte del discurso del ministro de Economía, Reconstrucción y Fomento, Pablo Baraona, en la inauguración del año académico de la Universidad de Concepción. Él señaló que era necesario un cambio radical en materia económica, puesto que los vicios y errores del pasado, no sólo durante el gobierno de la UP, fueron acumulados de tal forma que era necesario este giro en el rumbo de los destinos económicos de nuestro país (El Sur, 1 de abril de 1978, p. 5).

Durante este mismo periodo el crecimiento de capital, de crédito para Concepción y sus alrededores fue sustancialmente significativo, puesto que las dos entidades más grandes de la zona, Banco de Concepción y el Banco de Fomento Regional del Bío-Bío, lograron altos montos de dinero en dólares para convertirlos en colocaciones para sus clientes.

Hacia 1979 el entonces joven académico y director de la Escuela de Economía y Administración de la Universidad de Concepción, Joaquín Lavín Infante, daba cuenta de los beneficios que había traído al país la economía de mercado, basada principalmente en la libertad económica para poder emprender negocios y, por sobre todo, que los medios de producción y propiedad fueran privados, para que fueran los individuos libres los que decidieran cómo hacer de mejor forma las transacciones y, asimismo, que el papel del Estado consistiera sólo en establecer las reglas del juego y hacer que dichas reglas se cumplieran, lo demás quedaría en manos del mercado "libremente". En esa misma línea, será el propio Lavín Infante quien nuevamente insista en las ventajas y aciertos de la economía de mercado, esta vez con un lenguaje mucho más amigable, próximo y de fácil comprensión, en comparación con el utilizado por otros economistas (El Sur, 24 de septiembre de 1979, p. 2).

El sistema para la banca nacional sufrió nuevas reestructuraciones en 1980. La incorporación de las financieras a la ley de bancos, otorgando así

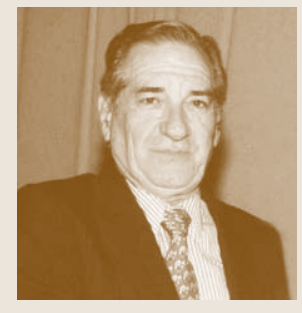

P. Baraona

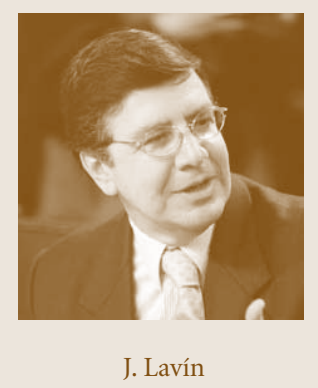

J. Lavín 
facultades antes exclusivas para estas entidades comerciales, es un punto importante a destacar para explicar el gran crecimiento del sistema financiero; además, las facultades comerciales para los bancos de fomento constituye una medida que permite entender cómo se fue armando el proceso de construcción de la multibanca nacional y donde el "Gran Concepción”, caracterizado como una zona de importante desarrollo empresarial e industrial para el país, fue un actor de primordial experimentación en el contexto neoliberal que vivió la economía chilena a comienzos de los años ochenta, donde la premisa más importante para los organismos económicos de la dictadura fue "regionalizar la economía nacional".

A principios de la década del ' 80 existía plena confianza entre la elite económica del "Gran Concepción" y los representantes de los multigremios de la zona de que la economía se mantendría firme y en franco crecimiento por los siguientes años (El Sur, 15 de noviembre de 1980, p. XVII). Las informaciones sobre repuntes económicos del país, gracias al modelo económico y su correcto manejo, fueron uno de los tópicos presentes por aquellos días, también el análisis económico de los representantes de la elite intelectual perteneciente al mundo de la economía, como lo revelan los informes de Emilio Sanfuentes y luego de Andrés Sanfuentes, quienes bajo su mirada de especialistas o "expertos" (El Sur, 26 de diciembre de 1981, p. 8), alertaban sobre lo que podría pasar en un futuro cercano respecto del manejo económico que se estaba teniendo en Chile con temas como el cambio fijo del dólar (El Sur, 23 de noviembre de 1981, p. 3).

Por otro lado, en la ciudad de Concepción existió una tendencia a la creación de diversos bancos y financieras que llegaron a instalarse en el espacio económico local, aumentando la capacidad de crédito del mercado de capitales, funcionando al ritmo de un modelo económico que propiciaba la liberalización plena de la economía. Pero la situación de repunte y bonanza económica que trajo la economía de mercado se vio truncada frente al panorama económico internacional. La recesión que afectó a los Estados Unidos, sumada a la tendencia a la baja de los mercados europeo y oriental, más la crisis del petróleo internacional que va tomando forma durante aquellos años, dieron las primeras señales de alerta para la elite económica del "Gran Concepción". Muchas de sus actividades productoras estaban en directa relación con la economía internacional, como bien lo señalaba Ernesto Ezquerra, director del semanario Estrategia, quien, en una entrevista a la misma revista sobre el momento económico que vivía el país, aseguraba que la Octava Región sería una de las más golpeadas por la 
recesión internacional y que durante el año 1982 habría que ser cautelosos al momento de invertir, puesto que las condiciones y el alto costo del dinero no harían fácil el capitalizar de buena forma los recursos de las empresas y el mercado de capitales local (El Sur, 7 de octubre de 1981, p. 8).

Las mismas editoriales aparecidas en diario El Sur fueron claras al defender el mercado de capitales de la mínima acción preventiva que tuvieron las autoridades para resguardar el mercado de capitales nacional de una posible crisis, debido en parte al escenario económico antes descrito, y la indiscriminada libertad económica que se propugnó durante los primeros ocho años de dictadura (El Sur, 4 de diciembre de 1981, p. 3). Esta situación terminará por afectar los distintos sectores productivos nacionales, repercutiendo enormemente en la banca nacional, puesto que, al no poder pagar los clientes los créditos otorgados por los bancos, éstos se ven en serios déficits, ya que en muchos casos estos créditos representaban altos montos de la moneda norteamericana, la cual inundaba para esos años el mercado financiero de Chile, dando paso a lo que sería una devaluación progresiva de nuestra moneda nacional.

A finales de 1981 se desarrolló una serie de seminarios, donde se analizaba el momento económico y su repercusión en el espacio regional. Organizados principalmente por la Universidad de Concepción y la Sociedad de Estudios Económicos Géminis, se contaron con exposiciones de los mismos economistas que fueron parte del proceso de implementación del modelo económico. Es el caso de Pablo Baraona y Álvaro Bardón. Estos seminarios buscaron dar una mirada de certeza respecto al difícil momento que comenzaría a vivir el país durante 1982. La crisis ya estaba instalada. Ahora vendría el desenlace final.

\section{COMENTARIOS FINALES}

Los desaciertos del modelo económico de mercado fueron evidentes en la Región del Biobío. Diversos titulares comenzaron a publicarse indistintamente en las páginas de diario $E l$ Sur, haciendo evidente, en muchos casos, que el crecimiento económico no se había financiado con el ahorro efectivo de los clientes de los bancos y financieras, sino que con endeudamiento a través de créditos otorgados por estos mismos. Lo anterior, cabe señalar, fue pronosticado dos años antes por Emilio Sanfuentes en una columna de opinión, dando señales de alerta sobre el momento económico que se 
acercaba hacia principios de los años ochenta (El Sur, 22 de agosto de 1982, p. 2$)^{8}$.

Como señalamos en líneas anteriores, la recesión que golpeó a Chile en 1982 se hizo notablemente visible en los mercados de capitales, dando paso al quiebre de las empresas, lo que fue tangible desde finales de 1981. Pero, ¿qué ocurrió con la pujante elite económica del "Gran Concepción”? Es necesario resaltar que muchos de los principales negocios financieros de la región emigraron antes de la crisis a la capital del país, dejando sólo gerencias regionales en las distintas ciudades. El hecho es que los empresarios e industriales regionales se vieron abandonados y sobrepasados por deudas derivadas de los mercados de capitales, siendo ésta la tónica de los años posteriores; la quiebra y baja de salarios fue lo que golpeó fuertemente a las actividades productoras que se encontraban radicadas principalmente en las ciudades puerto de la región.

En consecuencia, encontramos una relación de distintos actores y procesos en los cuales se radicó, difundió y sociabilizó las ideas neoliberales. Esta correlación de actores regionales y capitalinos formó las relaciones de poder, por donde circularon las ideas neoliberales que tomaron forma casi sin restricción alguna hasta la crisis de 1983, golpeando fuertemente a una elite económica que tomaba forma en el espacio regional, la cual se había nutrido durante largos años de una economía liberalizada, ya sea a través de los espacios académicos, pero, sobre todo, de las autoridades políticas de turno que entregaron las pautas a través de las cuales se debía reactivar la actividad productiva regional.

\section{REFERENCIAS}

Dahse, F. (1979). Mapa de la extrema riqueza. Los grupos económicos y el proceso de concentración de capitales. Santiago de Chile: Editorial Aconcagua.

Hernández, H. (1983). "El Gran Concepción: Desarrollo histórico y estructura urbana. Primera parte. Génesis y evolución: De las fundaciones militares a la conurbación industrial”. Informaciones Geográficas, 30, 47-70.

Monsálvez A., D.; Pagola C., L. (2004). "Sueño, realidad y frustración: Banco de Fomento Regional del Bío-Bío, un proyecto de la élite económica

\footnotetext{
${ }^{8}$ Este artículo apareció originalmente el 27 de julio de 1980, pero dada la importancia de éste, diario El Sur decidió publicarlo por la coyuntura de 1982 respecto de la crisis que se estaba viviendo.
} 
del 'Gran Concepción' (1974-1982)”. Revista Austral de Ciencias Sociales, 26, 49-58.

Vergara, R. (1996). “Privatización de la banca: La experiencia chilena”. Estudios Públicos, 63, Invierno.

Vylder, S. (1985). "Chile 1973-84, consolidación y crisis del modelo neoliberal". Revista Ibero-Americana, Nordic Journal of Latin American Studies, vol. XV, $1-2$.

Diario El Sur de Concepción. Septiembre de 1973 a diciembre de 1983.

Diario Color de Concepción. Septiembre de 1973 a septiembre de 1976. 